\title{
A collaborative test of ion-exchange chromatographic methods for determining amino acids
}

\author{
By J. W. G. PORTER, D. R. WESTGARTH AND A. P. WILLIAMS \\ National Institute for Research in Dairying, Shinfield, Reading
}

(Received 4 October 1967-Accepted 8 February 1968)

\begin{abstract}
I. Collaborative assays to determine the amino acid content of a standard mixture of amino acids and of two test proteins, gelatin and freeze-dried cod muscle, were carried out to assess the accuracy of the ion-exchange column chromatographic technique as operated in different laboratories.

2. Nine laboratories took part, four using single-column automatic amino acid analysers, three using two-column automatic amino acid analysers and two using the manual procedure.

3. In the assay of the amino acid mixture the percentage mean absolute deviations in laboratories using single-column and two-column automatic amino acid analysers, and in one laboratory using the manual method, were $4 \cdot 8,2 \cdot 2$ and $6 \cdot 8$ respectively.

4. In the assay of acid-hydrolysates of cod muscle the percentage absolute mean deviations from the mean value in laboratories using two-column automatic amino acid analysers were $7.2,2.9$ and 9.4 for single-column and two-column automatic amino acid analysers and the manual method, respectively.

5. The corresponding values in the assay of hydrolysates of gelatin were $7 \cdot 6,3.7$ and $6 \cdot I$, respectively.

6. Possible explanations are put forward for the different degrees of precision achieved by the methods used.
\end{abstract}

For many years the lack of a reasonably quick and reliable quantitative method for the analysis of amino acids hindered research into the chemical and nutritional properties of proteins. However, the development of the ion-exchange column chromatographic techniques by Moore \& Stein (195I, I954a) made it possible to determine the amino acid composition of as little as $2.5 \mathrm{mg}$ of protein in I week with an accuracy of $\pm 3 \%$. Bender, Palgrave \& Doell (1959) carried out a collaborative test to assess the accuracy of these techniques as carried out by workers in ten different laboratories. The results showed a high degree of consistency and agreement between the different laboratories in analyses of amino acid mixtures, but tests were not carried out with proteins so no information was available about the influence of acid hydrolysis of proteins on the reproducibility of the procedure.

In 1958 Spackman, Stein \& Moore described an improved system for the accelerated chromatography of amino acids on ion-exchange resins. Complete amino acid analysis of protein hydrolysates was performed in $24 \mathrm{~h}$ using automatic recording equipment and a precision was achieved equal to that of the earlier procedure. Since $195^{8}$ many laboratories have started to use automatic amino acid analysers and the aim of the present collaborative test was to assess the precision of the procedure as carried out in seven different laboratories and to compare the results with those obtained by the manual procedure used by two other laboratories. The idea of this test arose among members of the Agricultural Research Council Group on Tests of Protein Quality but those who agreed to participate were both within and without the Group. 
In the earlier collaborative test (Bender et al. 1959) laboratories analysed a single test solution prepared from pure amino acids, combined in proportions approximating to those in total milk proteins. The scope of the present test was widened by analysing for the amino acid composition of two protein-rich materials as well as an amino acid mixture of known composition.

The following workers took part:

J. Bunyan, Vitamins Ltd, Walton Oaks Experimental Station, Dorking Road, Tadworth, Surrey.

D. C. Cusworth, University College Hospital Medical School, University Street, London WC $\mathrm{r}$.

A. G. Davison, Unilever Ltd, Colworth House, Sharnbrook, Bedford.

R. Dawson, Rowett Research Institute, Bucksburn, Aberdeen.

J. P. F. D'Mello, University of Nottingham, School of Agriculture, Sutton Bonington, Loughborough, Leics.

J. S. Pierce, A. Guinness, Son and Co. Ltd, Park Royal Brewery, London NW io.

M. P. Read, J. Bibby and Sons Ltd, Nutrition Research and Advisory Departments, Neston, Wirral, Cheshire.

J. Williams, Spillers Ltd, Central Laboratory, Station Road, Cambridge.

A. P. Williams, National Institute for Research in Dairying, Shinfield, Reading.

\section{EXPERIMENTAL}

\section{Materials}

Amino acid mixture. A standard solution of L-amino acids (AR grade) in $0.2 \mathrm{M}$ sodium citrate buffer at $\mathrm{pH} 2 \cdot 2$ containing per $\mathrm{ml} \mathrm{I} \mu$ mole $( \pm 0 . \mathrm{I} \%)$ of each of the following amino acids: tryptophan, lysine, histidine, arginine, aspartic acid, threonine, serine, glutamic acid, glycine, alanine, valine, methionine, isoleucine, leucine, tyrosine, phenylalanine and $2 \mu$ moles $( \pm 0 \cdot 1 \%$ ) of proline (Evans Electroselenium Limited, Halstead, Essex).

Test proteins. Each collaborating laboratory received $5 \mathrm{~g}$ of freeze-dried cod muscle (kindly provided by Dr E. L. Miller, University of Cambridge School of Agriculture, Cambridge) and $2 \mathrm{~g}$ of commercial ox-hide gelatin.

\section{Methods}

Each laboratory was asked to use its customary procedure for hydrolysis, amino acid analysis and nitrogen determination. Details of the procedures used by individual laboratories are given in Table $\mathrm{I}$.

\section{RESULTS AND DISCUSSION}

\section{Standard amino acid mixture}

The standard mixture of amino acids was made up to contain $2 \mu \mathrm{moles} / \mathrm{ml}$ of proline and $\mathrm{r} \mu \mathrm{mole} / \mathrm{ml}$ of each of the remaining fifteen amino acids. Table 2 shows the percentage deviation between each laboratory's estimate and the expected value. Mean deviations, $\%$, are shown for each laboratory by averaging over the deviations of 


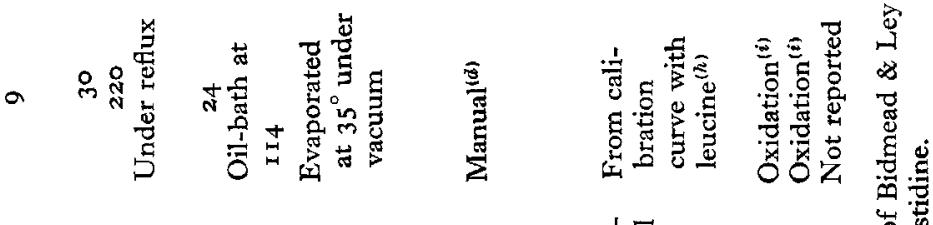

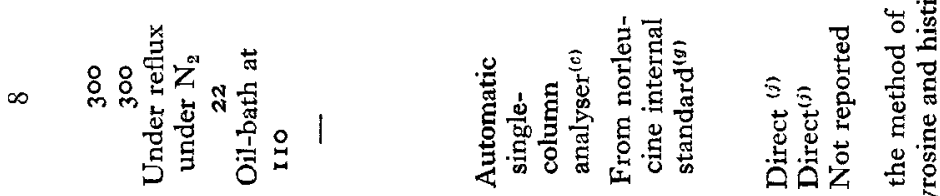

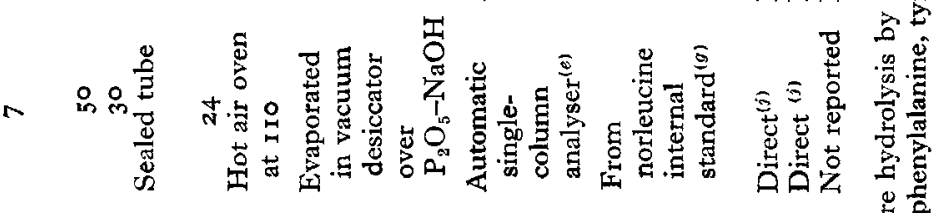

总

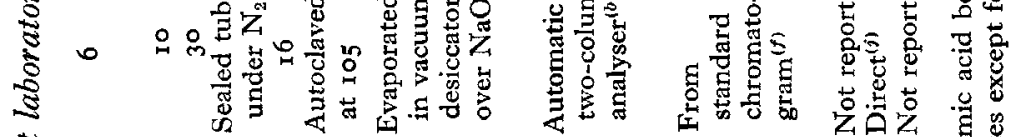

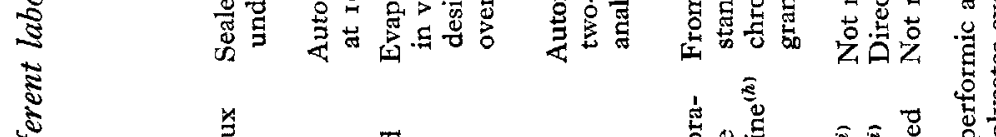

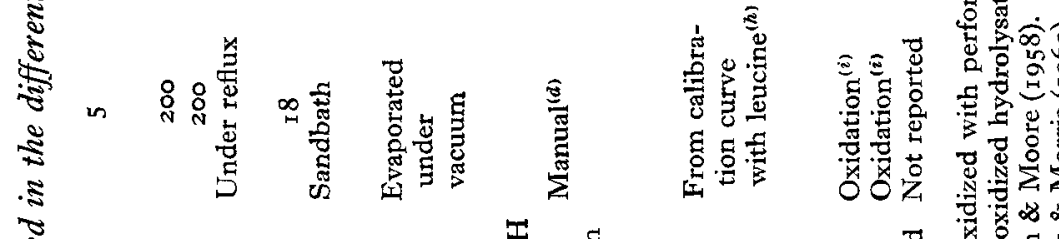

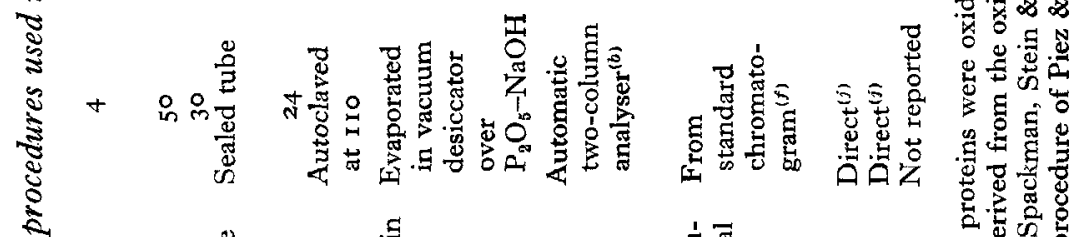

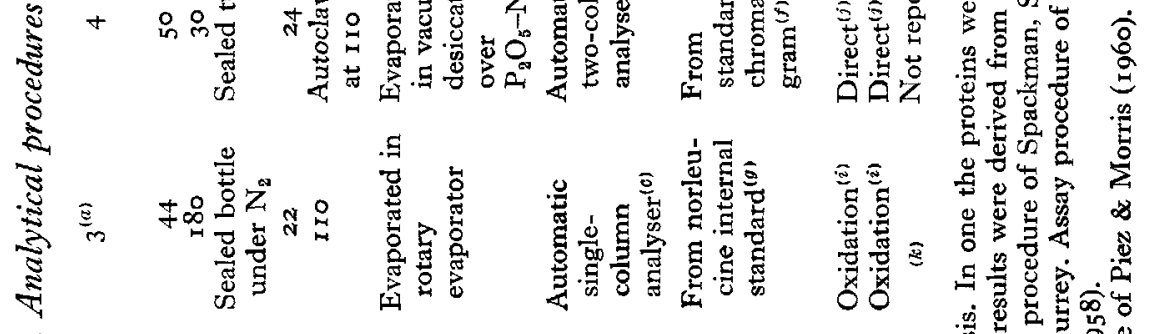

兽

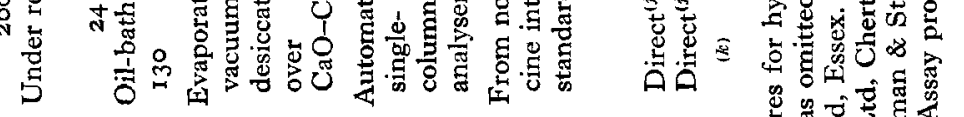

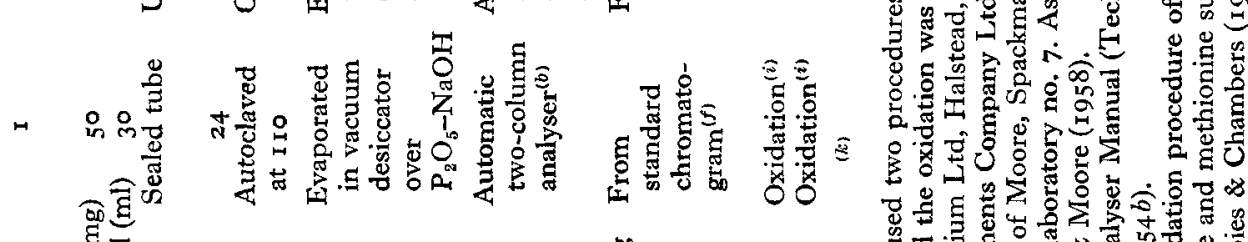

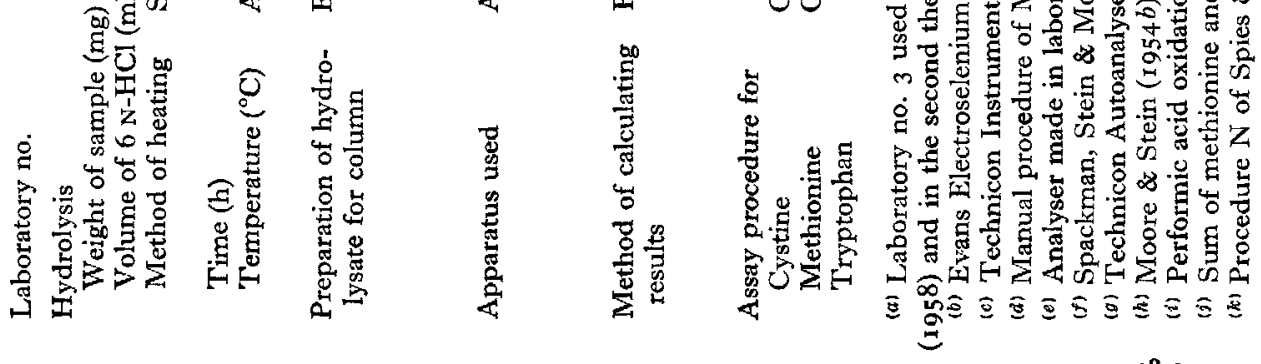




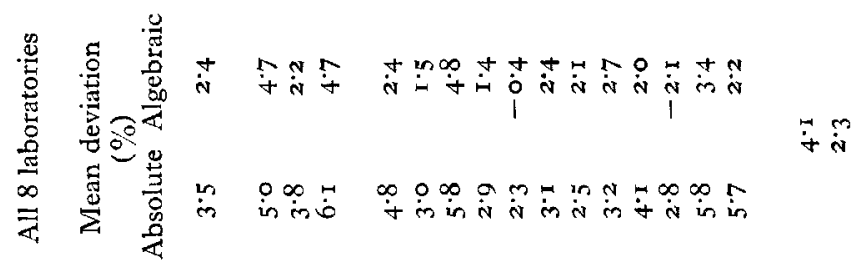

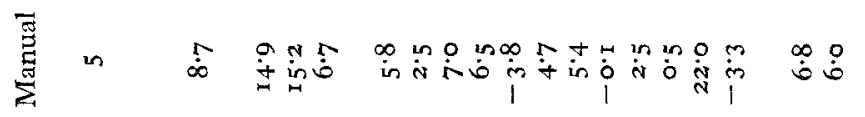

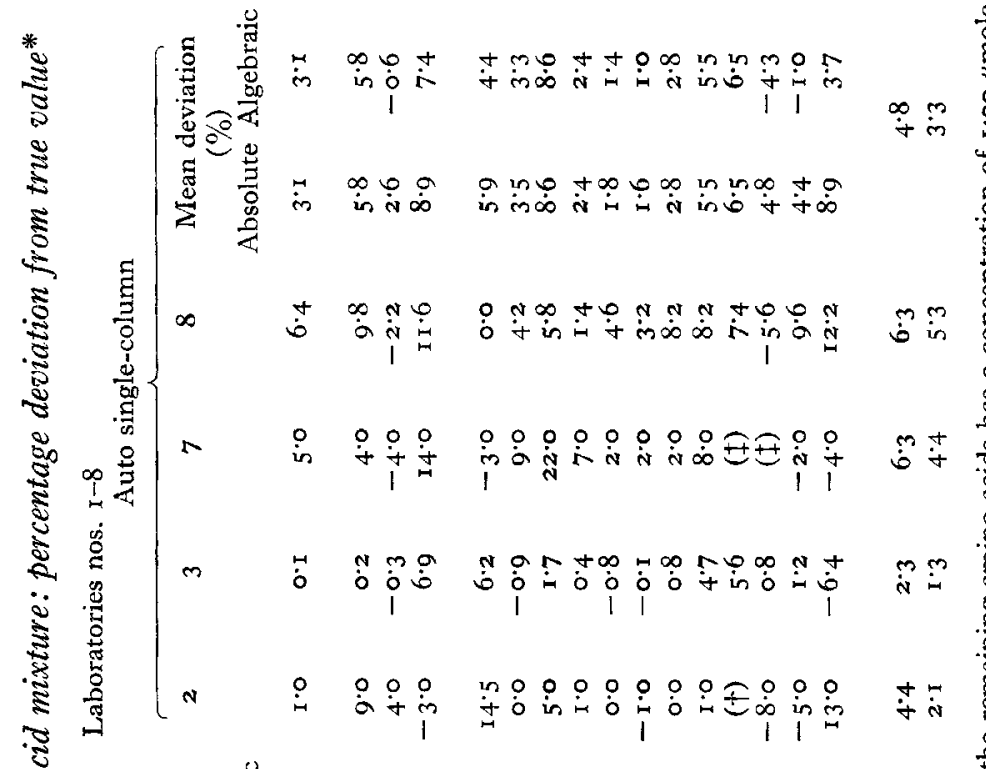

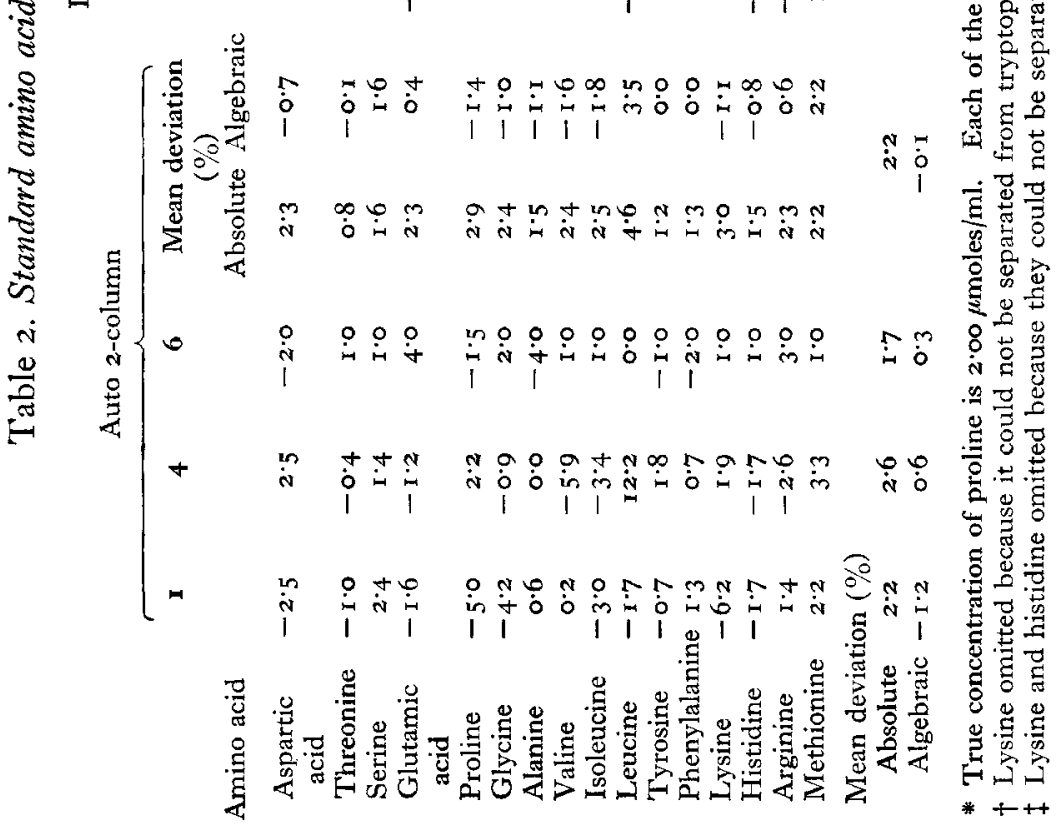


individual amino acids. The mean algebraic deviation, $\%$, is the arithmetic mean of individual deviations and is a measure of the laboratory's bias; the mean absolute deviation, $\%$, is the average taken regardless of sign and is an overall measure of the dispersion about the true values.

Table 2 (penultimate row) shows that the laboratories using automatic two-column analysers and laboratory no. 3 using an automatic single-column analyser each had mean absolute deviations less than $3 \%$. The four remaining laboratories, including no. 5 using the manual method, had mean deviations ranging from about 4 to $7 \%$. The average value for the eight laboratories is $4 . \mathrm{I} \%$. Laboratory no. 3 with the highest accuracy and precision of the automatic single-column users was exceptional in adopting at least seven replicates for each amino acid determination in contrast to the two or three employed by other laboratories.

These mean absolute deviations for individual laboratories showed an improvement over those of an earlier collaborative test on a standard mixture reported by Bender et al. (1959). The numbers of laboratories in the two tests having mean absolute deviations, $\%$, within given limits are as follows:

$\begin{array}{ccc}\begin{array}{c}\text { Mean absolute } \\ \text { deviation (\%) }\end{array} & \text { From Table 2 } & \begin{array}{c}\text { From Bender } \\ \text { et al. (I959) }\end{array} \\ 0 \cdot 0-2 \cdot 5 & 3 & 0 \\ 2 \cdot 5-5 \cdot 0 & 2 & 5 \\ 5 \cdot 0-7 \cdot 5 & 3 & 3 \\ 7 \cdot 5-10 \cdot 0 & \circ & 0 \\ 10 \cdot 0 \text { or greater } & 0 & 3 \\ \text { Total no. of } & 8 & \text { II } \\ \text { laboratories } & & \\ \text { Mean deviation } & 4.1 \% & 6 \cdot 9 \%\end{array}$

The number of replicate determinations per amino acid estimate varied in different laboratories but averaged about three in the present study and that of Bender et al. (1959).

The average bias of each laboratory, as measured by the mean algebraic deviation, $\%$, is given in the final row of Table 2. Only one of the eight laboratories had a negative bias, and averaging over all laboratories the bias was $+2.3 \%$. Automatic twocolumn laboratories had less bias than others and their average was $-0.1 \%$.

The rankings of the eight laboratories in terms of absolute and algebraic mean deviations, $\%$, were in close agreement.

Examining the performance of each laboratory with individual amino acids shows that laboratories 2, 7,8 and 5 determined only about half the amino acids within $\pm 5 \%$ of the true values, whereas laboratories $I, 4,6$ and 3 determined over half within $\pm 2 \%$. The average laboratory determined $40 \%$ of the amino acids within $\pm 2 \%$ limits and about $70 \%$ within $\pm 5 \%$ limits.

If, when calculating deviations, the known concentrations of amino acids in the mixture were replaced by estimates obtained by averaging the results of the laboratories using two-column automatic amino acid analysers, the general pattern of deviations remained in broad agreement with that of Table 2. This is not surprising since the bias or mean algebraic deviation, \%, of the results of this group of laboratories is 
442 J. W. G. Porter, D. R. Westgarth and A. P. Williams 1968 shown in Table 2 to be small. The replacement of known concentrations of amino acids by such estimates favours laboratories using two-column automatic analysers, but only slightly; for example, the mean absolute deviation of the group was reduced from $2.2 \%$ (see Table 2 ) to $2.0 \%$, and the mean algebraic deviation changed from $-0.1 \%$ to a theoretical value of zero.

\section{Cod muscle}

True concentrations of amino acids in cod muscle are not known and the percentage deviation for each laboratory was calculated from the concentration of amino acid ( $\mathrm{g} / \mathrm{I} 6 \mathrm{~g} \mathrm{~N}$ ) obtained by averaging results of the laboratories using automatic twocolumn amino acid analysers. These percentage deviations are shown in Table 3 . An additional laboratory, no. 9, using manual methods is included.

Table 3 (penultimate row) shows that laboratories using automatic two-column amino acid analysers had absolute mean deviations of about $3 \%$, whereas laboratories using single-column amino acid analysers had values of about $7 \%$. Both figures are somewhat larger than those obtained with the standard amino acid mixture. Of the laboratories using the manual procedure, the precision of no. 5 approached that of laboratories using single-column amino acid analysers, but no. 9 had a mean deviation of about $20 \%$. The mean absolute deviation for the nine laboratories was $7 \cdot 4 \%$, or $5.8 \%$ if laboratory no. 9 is excluded.

Three laboratories, nos. 6,7 and 9 , had negative mean algebraic deviations. The ranking of the laboratories in terms of magnitude of bias was in good agreement with that based on their mean absolute deviations (\%).

Thus, although the results with cod muscle were poorer than those with the standard amino acid mixture, the average laboratory determined about $60 \%$ of the amino acids within $\pm 5 \%$ deviation and about one-quarter within $\pm 2 \%$.

\section{Gelatin}

Deviations of determinations of amino acids in gelatin are shown in Table 4. True concentrations of the amino acids were unknown and estimates obtained by averaging results of the laboratories using automatic two-column amino acid analysers were used. Tyrosine and methionine were present in relatively small quantities, and the associated percentage deviations shown in Table 4 are large and variable. Consequently, the laboratory mean deviations have been calculated with and without these two amino acids.

When tyrosine and methionine were excluded the mean absolute deviations of the laboratories using automatic two-column amino acid analysers averaged about $4 \%$ and those of the laboratories using single-column amino acid analysers averaged about $8 \%$ (despite laboratory no. 7 which had a value of $14 \%$ ). Laboratory no. 5 using the manual procedure had a mean absolute deviation comparable with those of laboratories using single-column amino acid analysers, but laboratory no. 9 again had a value of about $20 \%$. The average value for the nine laboratories is $7.5 \%$, or $5.9 \%$ if laboratory no. 9 is excluded. When tyrosine and methionine are included the mean absolute deviation, \%, of each laboratory is markedly increased and, on average, is approxi- 
Vol. 22

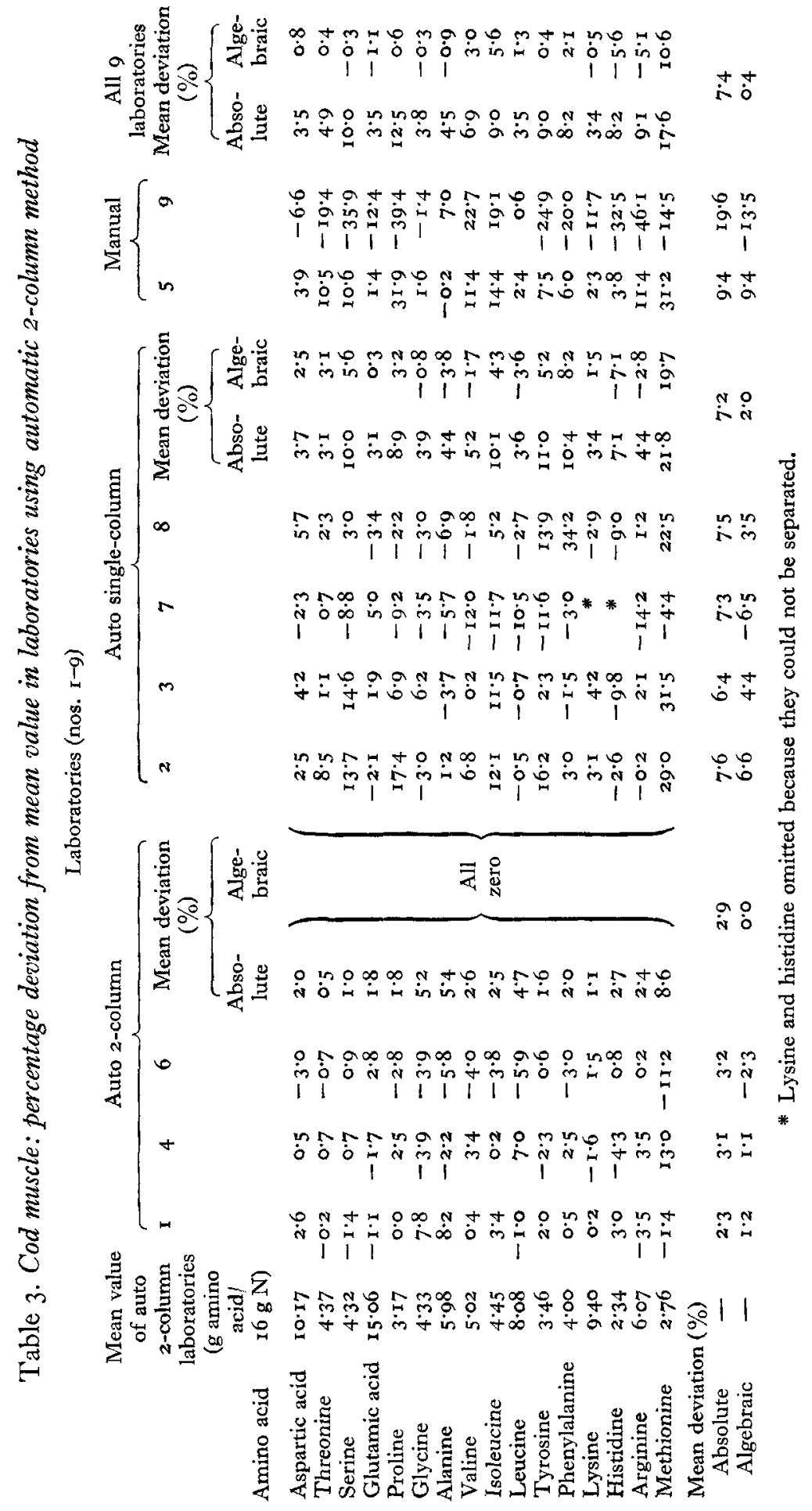




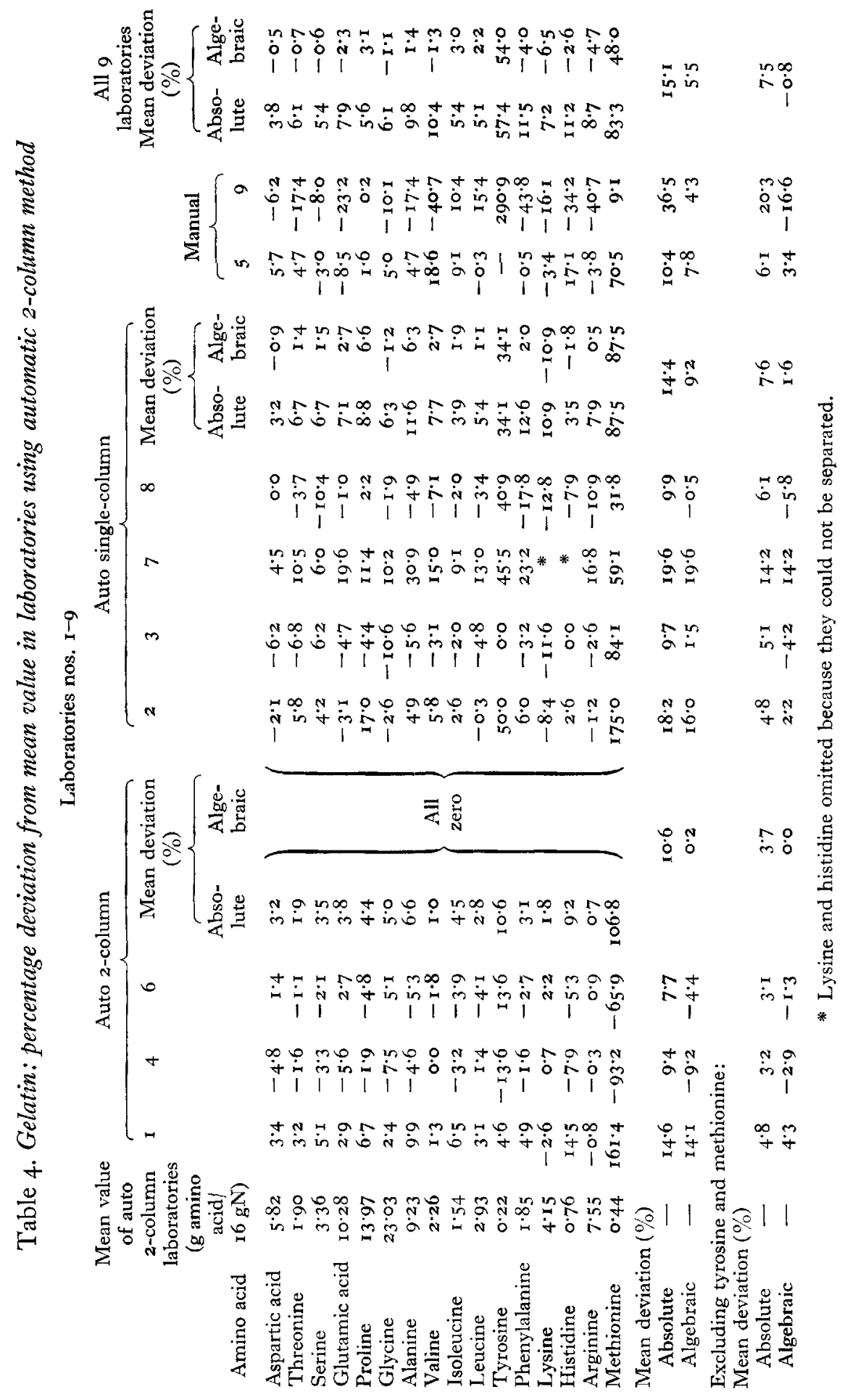


mately doubled. However, the general order of precision between types of laboratory still applies.

The mean algebraic deviation for the nine laboratories is only $-0.8 \%$, or $+5.5 \%$ if tyrosine and methionine are included. Laboratory no. 7 shows an unexpectedly large mean algebraic deviation of $+14.2 \%$ (excluding tyrosine and methionine) and its deviations for individual amino acids were all positive.

The average laboratory determined about half the amino acids in gelatin within $\pm 5 \%$ and about one-sixth within $\pm 2 \%$. No laboratory succeeded in determining both tyrosine and methionine within \pm 10\% limits.

\section{Comparison of mean deviations obtained with standard amino acid mixture, cod muscle and gelatin}

Mean deviations obtained with each test material and averaged over laboratories nos. I-8 are summarized in the final column of Table 5. Results from laboratory no. 9 are omitted because it did not participate in the tests with the standard amino acid mixture.

Table 5. Mean deviations* obtained with the test substances in laboratories nos. 1-9, using 2-or single-column automatic amino acid analysers or the manual procedure

\begin{tabular}{|c|c|c|c|c|c|c|}
\hline \multirow[b]{3}{*}{ Test substance } & \multicolumn{2}{|c|}{ Automatic } & & & & \\
\hline & \multirow{2}{*}{$\begin{array}{c}2- \\
\text { column } \\
(1,4,6)\end{array}$} & \multirow{2}{*}{$\begin{array}{c}\text { Single- } \\
\text { column } \\
(2,3,7,8)\end{array}$} & \multicolumn{2}{|c|}{ Manual } & \multicolumn{2}{|c|}{$\underbrace{\text { Mean }}$} \\
\hline & & & 5 & 9 & $I-9$ & $1-8$ \\
\hline \multicolumn{7}{|c|}{ Mean absolute deviation $(\%)$} \\
\hline $\begin{array}{l}\text { Standard mixture } \\
\text { (Table 2) }\end{array}$ & $2 \cdot 2$ & $4 \cdot 8$ & $6 \cdot 8$ & - & - & $4^{\cdot 1}$ \\
\hline Standard mixture* & $2 \cdot 0$ & $5 \cdot 3$ & 7.0 & - & - & 43 \\
\hline Cod muscle (Table 3 ) & $2 \cdot 9$ & $7 \cdot 2$ & 9.4 & $19 \cdot 6$ & $7 \cdot 4$ & 5.8 \\
\hline Gelatin (Table 4) & 10.6 & $14: 4$ & 10.4 & $36 \cdot 5$ & $15 \cdot 1$ & 12.4 \\
\hline $\begin{array}{l}\text { Gelatin (Table } 4 \text { ) } \\
\text { (excluding tyrosine a }\end{array}$ & $\begin{array}{c}3 \cdot 7 \\
\text { ad methio }\end{array}$ & ine) ${ }^{7 \cdot 6}$ & $6 \cdot \mathbf{I}$ & $20 \cdot 3$ & $7 \cdot 5$ & $5 \cdot 9$ \\
\hline
\end{tabular}

Mean algebraic deviation (\%)

\begin{tabular}{|c|c|c|c|c|c|c|}
\hline (a) Standard mixture & -0.1 & $+3 \cdot 3$ & +6.0 & - & - & $+2 \cdot 3$ \\
\hline (b) Standard mixture & zero & $+3 \cdot 3$ & $+6 \cdot 0$ & - & $\longrightarrow$ & $+2 \cdot 4$ \\
\hline (c) Cod muscle & zero & $+2 \cdot 0$ & $+9 \cdot 4$ & -13.5 & +0.4 & $+2 \cdot 2$ \\
\hline (d) Gelatin & zero & $+9 \cdot 2$ & $+7 \cdot 8$ & +43 & +5.5 & +5.6 \\
\hline (e) Gelatin & zero & $+I \cdot 6$ & $+3 \cdot 4$ & -16.6 & -0.8 & \\
\hline
\end{tabular}

\footnotetext{
* All deviations are measured from the mean automatic 2-column value, except in $(a)$.
}

The mean absolute deviation was about $4 \%$ for the standard mixture (measuring deviations from the known concentrations or from the mean for automatic two-column analysers) whereas a value of about $6 \%$ was obtained with cod muscle and over $12 \%$ with gelatin. When tyrosine and methionine are excluded from the gelatin results, the mean absolute deviation is reduced from 12 to $6 \%$.

Mean algebraic deviations were approximately $+2 \%$ for the standard mixture and for cod muscle but increased to almost $+6 \%$ with gelatin. 
Table 5 also shows that with each test material mean absolute deviations were larger with single-column than with two-column analysers, although the latter derived some unmerited advantage in the cod muscle and gelatin tests because all deviations are then measured from the mean concentrations indicated by two-column analysers. Mean absolute deviations of manual laboratory no. 9 were large but the performance of the other manual laboratory, no. 5, was roughly comparable with that of single-column analysers.

Adjustment for bias. The average bias of the automatic two-column analysers was negligible with the standard mixture and has been assumed to be zero with cod muscle and gelatin. The remaining five laboratories participating in the tests with the standard mixture showed positive bias. The possibility of adjusting the cod-muscle and gelatin results of these five laboratories with the aid of the bias established with the standard mixture has been examined.

For each of these five laboratories, a corrected deviation for a given amino acid in cod muscle or gelatin was calculated by first adjusting the observed concentration for the bias experienced with the same amino acid in the standard mixture. The percentage deviation of this adjusted concentration from the mean observed concentration with automatic two-column analysers gave the adjusted percentage deviation. Mean absolute deviations were then calculated as usual for each laboratory.

For the tests on cod muscle the adjustment reduced the mean absolute deviation in only three out of the five laboratories and left the average value for the five laboratories unchanged at $7 \cdot 6 \%$. With gelatin only two out of five laboratories benefited from the adjustment and the average value deteriorated slightly from $7 \cdot 3$ to $7 \cdot 6 \%$. This failure of the adjustment to produce a general improvement arose because the bias shown by a laboratory in determining a given amino acid was not consistent with the three test materials.

As a corollary to this failure to establish some degree of consistency in bias, it should be noted that the negligible mean algebraic deviation, \%, for automatic two-column analysers in the standard mixture tests does not necessarily imply negligible mean bias with other test substances, as assumed in Tables 3 and 4 . However, it is probably safe to assume that the true mean bias of this group of laboratories was likely to be less than that of the other laboratories.

Accuracy of estimation of different amino acids. Throughout this paper deviations are expressed as percentages of the concentration of the particular amino acid. In the case of the standard amino acid mixture the choice of this percentage form is immaterial since all the amino acids, except proline, were present in equal concentration. With the cod muscle, concentrations varied from about 2 to $15 \mathrm{~g} / \mathrm{i} 6 \mathrm{~g} \mathrm{~N}$ and there was a strong tendency for amino acids present in lower concentrations to have higher percentage deviations. The regression of mean absolute deviation, \% (Table 3 , penultimate column), on the reciprocal of the amino acid mean concentration was significant with a regression coefficient of $28 \cdot 8 \pm 7 \cdot 5$.

However, this does not fully accord with the pattern of the gelatin results. Methionine and tyrosine have very low concentrations and their mean absolute deviations, $\%$, were extremely high, but the remaining fourteen amino acids reveal no such relation- 
ship, despite a range of concentrations from 0.8 to $23.0 \mathrm{~g} / \mathrm{1} 6 \mathrm{~g} \mathrm{~N}$. The regression coefficient relating the mean absolute deviations, \%, of the fourteen amino acids with the reciprocals of their concentrations was $3.09 \pm 1 \cdot 93$ and was not significant.

Consistency in the relative accuracy of estimating different amino acids. The accuracy of estimation of the sixteen amino acids in the standard mixture has been ranked within each of the laboratories using the percentage deviations (regardless of sign) given in Table 2. The rankings of the amino acids have then been compared for the eight laboratories to determine whether there was some measure of consistency. No such agreement was established (coefficient of concordance, $W=0.14$ with probability $P>0.1$ ).

In a similar test of concordance between rankings of the sixteen amino acids within each of nine laboratories participating in the trial on the cod muscle significance at the $5 \%$ level was not established, but some level of agreement was indicated $(W=\mathrm{r} \cdot 64$ with $0.05<P<0.10$ ). The varying amino acid concentrations in cod muscle and their effect on percentage deviations doubtless contributed to this indication of agreement.

Comparing the rankings of sixteen amino acids in nine laboratories for the gelatin revealed significant agreement $(W=0.29$ with $P<0.001)$, but this arose primarily because most laboratories experienced marked percentage inaccuracies in estimating tyrosine and methionine. When these two amino acids were omitted no significant agreement between the rankings within laboratories was shown $(W=0.14$ with $P>0 \cdot 1)$. Again this accorded with the remarks in the previous section on the effect of amino acid concentration in the gelatin.

If the tests of concordance for cod muscle and gelatin were confined to the eight laboratories collaborating in the standard mixture trial, the conclusions are essentially the same as those obtained with nine laboratories.

Replicate determinations within laboratories. Each laboratory's estimate of the concentration of a given amino acid was the mean of a number of replicate determinations. The number of replicates per amino acid were usually as follows:

$\begin{array}{llcccccccc}\text { Laboratory no. } & \text { I } & 2 & 3 & 4 & 5 & 6 & 7 & 8 & 9 \\ \text { Standard mixture } & 2 & (2) & (7) & (1) & 3 & (2) & 2 & 2 & -2 \\ \text { Cod muscle } & 2 & 2 & (\text { IO) } & 3 & 3 & 2 & 2 & 2 & 2 \\ \text { Gelatin } & 2 & 2 & (8) & 3 & 4 & 2 & 2 & 2 & 3\end{array}$

For the standard mixture a pooled estimate of the standard deviation, $s$, between replicates within laboratories was calculated for each amino acid. Replicates shown above in parentheses were excluded because values of individual determinations were not readily available or, in the case of laboratory no. 3 , because differences between replicates included some comparison of method (see footnote (a), Table r). Expressing $s$ as a percentage of the true concentration gave a percentage coefficient of variation for each amino acid. The coefficients of variation ranged from $2 \cdot 2$ to $10.1 \%$ and, averaged over the sixteen amino acids, had a mean value of $4.6 \%$.

Coefficients of variation between replicates were calculated similarly for the codmuscle and gelatin tests except that the true concentration of each amino acid was replaced by the mean concentration obtained from automatic two-column analysers. 
448 J. W. G. Ponter, D. R. Westgarth and A. P. Williams ig68

The average value of the coefficients in the cod-muscle tests was $3.2 \%$ and in the gelatin tests was $6.7 \%$, or $4.9 \%$ if tyrosine and methionine were excluded. Coefficients of variation within laboratories using automatic single-column analysers did not differ markedly from those with two-column analysers.

If a laboratory's estimate of the percentage deviation of a given amino acid in the standard mixture is $d \%$, then the $95 \%$ confidence limits are approximately $d \pm(2 c)$ $\sqrt{ } n) \%$, where $c$ is the percentage coefficient of variation between replicates and $n$ is the number of replicates.

For example, estimation of histidine in the standard mixture in laboratory no. 2:

$$
\begin{aligned}
& d=-8.0 \% \text { (see Table } 2) \\
& c=4.6 \% \text { (pooled value for standard mixture) } \\
& n=2 \text { in laboratory no. } 2 .
\end{aligned}
$$

Then $95 \%$ confidence limits are $-8 \cdot 0 \pm 6 \cdot 5 \%=-14.5$ to $-1 \cdot 5 \%$.

Hence $d$ differs significantly from zero and the laboratory may be judged to have shown significant negative bias in the estimation of histidine. If this test of significance is applied to the percentage deviations shown in Table 2 it is evident that significant bias is not established with automatic two-column analysers, with the sole exception of the leucine estimation in laboratory no. 4. Several examples of significant bias occur in the results of the remaining laboratories.

\section{Cystine, methionine and tryptophan}

The determination of the cystine, methionine and tryptophan content of proteins by the standard procedure as used for the other amino acids is generally unsatisfactory owing to their instability during acid hydrolysis. Suitable modifications of the standard procedure or the alternative methods used are shown in Table I. The results obtained in the different laboratories are given in Table 6.

\section{Nitrogen recovery}

The total amount of nitrogen recovered as amino acids from cod muscle and from gelatin in each laboratory was calculated. The results are compared in Table 7 with the total nitrogen content of the proteins as determined by the Kjeldahl procedure. In compiling this table it was necessary in a few instances to use the mean values of the results from the laboratories that had made particular determinations, such as that of hydroxyproline in gelatin, to fill in gaps in the results from other laboratories. Likewise, owing to loss of records, mean values were taken for the total nitrogen content of the proteins used in laboratories nos. 7 and 9 .

\section{General conclusions}

It is evident from the findings of this collaborative test that satisfactorily uniform results can be obtained by workers using automatic amino acid analysers, and that experienced workers using the manual procedure can achieve broadly similar results. Moreover, it is evident from the statistical analysis that in this collaborative test the mean absolute deviations of individual laboratories in the analysis of the standard 
amino acid mixture were smaller than those in the earlier trial reported by Bender $e t$ al. (1959). This improvement is undoubtedly due to the introduction and use of automatic amino acid analysers which give a better separation of peaks on the chromatogram and which, operating with all the solutions enclosed within the system and thus eliminating contamination by dust and ammonia from the laboratory atmosphere, give a more stable base-line than can be obtained with the manual procedure. Furthermore, the continuously measured and more stable base-line allows more accurate assessments to be made of the small peaks given by amino acids present in low concentrations.

Table 6. Cystine, methionine and tryptophan contents of cod muscle and gelatin as determined in laboratories nos. 1-9

\begin{tabular}{|c|c|c|c|c|c|c|c|c|c|}
\hline Laboratory no. & $\mathbf{I}$ & 2 & 3 & 4 & 5 & 6 & 7 & 8 & 9 \\
\hline $\begin{array}{l}\text { Cystine } \\
\text { (a) Cod muscle } \\
\text { (b) Gelatin }\end{array}$ & $\begin{array}{l}\mathbf{r} \cdot 05 \\
0.00\end{array}$ & $\begin{array}{l}1.20 \\
-\end{array}$ & $\begin{array}{l}\mathrm{I} \cdot \mathrm{I} 5 \\
0.06\end{array}$ & - & $\begin{array}{l}1.43 \\
0.06\end{array}$ & - & $\stackrel{0.31}{-}$ & $\begin{array}{l}0.33 \\
0.00\end{array}$ & $\begin{array}{l}1 \cdot 06 \\
0.12\end{array}$ \\
\hline $\begin{array}{l}\text { Methionine: } \\
\text { (a) Cod muscle } \\
\text { (b) Gelatin }\end{array}$ & $\begin{array}{l}2 \cdot 72 \\
1 \cdot 15\end{array}$ & $\begin{array}{l}3.56 \\
\text { I. } 21\end{array}$ & $\begin{array}{l}3 \cdot 63 \\
0.81\end{array}$ & $\begin{array}{l}3.12 \\
0.03\end{array}$ & $\begin{array}{l}3 \cdot 62 \\
0.75\end{array}$ & $\begin{array}{l}2.45 \\
0.15\end{array}$ & $\begin{array}{l}2.64 \\
0.70\end{array}$ & $\begin{array}{l}3 \cdot 38 \\
0.58\end{array}$ & $\begin{array}{l}2 \cdot 36 \\
0 \cdot 48\end{array}$ \\
\hline $\begin{array}{l}\text { Tryptophan: } \\
\text { (a) Cod muscle } \\
\text { (b) Gelatin }\end{array}$ & $\begin{array}{l}r \cdot 06 \\
0.00\end{array}$ & $\begin{array}{l}\mathbf{I} 3 \mathbf{I} \\
0.00\end{array}$ & $\begin{array}{l}0.76 \\
0.00\end{array}$ & - & - & - & - & - & 1.09 \\
\hline
\end{tabular}

Table 7. Total nitrogen contents of cod muscle and gelatin and the calculated amounts of amino acid- $N$ and ammonia- $N$ recovered during ion-exchange chromatography

\begin{tabular}{|c|c|c|c|c|c|c|c|c|c|}
\hline Laboratory no. & $\mathbf{I}$ & 2 & 3 & 4 & 5 & 6 & 7 & 8 & 9 \\
\hline \multicolumn{10}{|c|}{ Cod muscle } \\
\hline Total N (g) & $14 \cdot 60$ & 14.60 & 14.60 & $\mathrm{r}_{4} .60$ & $14 \cdot 16$ & $14-48$ & 14.47 & $14 \cdot 3^{\circ}$ & $14 * 47$ \\
\hline $\begin{array}{l}\text { Amino acid-N } \\
\text { (recovery } \% \text { ) }\end{array}$ & 83.40 & 85.80 & 85.00 & $83 \cdot 20$ & $88 \cdot 50$ & $81 \cdot 50$ & 73.90 & $82 \cdot 60$ & 70.90 \\
\hline $\begin{array}{l}\text { Ammonia-N } \\
\text { (recovery } \% \text { ) }\end{array}$ & $7 \cdot 30$ & $5 \cdot 60$ & $7 \cdot 30$ & $7 \cdot 30$ & $9 \cdot 20$ & $7 \cdot 20$ & 730 & $7 \cdot 30$ & $7 \cdot 30$ \\
\hline \multicolumn{10}{|c|}{ Gelatin } \\
\hline Total N (g) & $15 \cdot 30$ & 15.24 & I 5.80 & $15 \cdot 30$ & $15 \cdot 16$ & $15 \cdot 34$ & $15 \cdot 29$ & 14.90 & r 5.29 \\
\hline $\begin{array}{c}\text { Amino acid-N } \\
\text { (recovery } \%)\end{array}$ & $100 \cdot 50$ & $99 \cdot 10$ & $91 \cdot 30$ & 93.60 & $97 \cdot 60$ & $97 \cdot 60$ & 107.30 & 93.40 & 84.40 \\
\hline $\begin{array}{l}\text { Ammonia-N } \\
\text { (recovery \%) }\end{array}$ & $2 \cdot 30$ & 3.10 & $2 \cdot 40$ & $2 \cdot 40$ & $2 \cdot 60$ & $x-80$ & $2 \cdot 40$ & $2 \cdot 40$ & 2.40 \\
\hline
\end{tabular}

Greater mean absolute deviations were obtained with the test proteins, cod muscle and gelatin, than with the standard amino acid mixture. This finding, which was not unexpected, was clearly due primarily to errors introduced by hydrolysis of the proteins. Each laboratory used its customary procedure for the hydrolysis of the proteins and although these procedures differed slightly (see Table I) it is not possible to establish any relationship between the method used and the results obtained in the analysis for amino acids.

Thus the indications from this trial are that satisfactory agreement can be obtained in routine determinations of the amino acid composition of proteins.

It was not possible in this investigation to seek the greater accuracy that can be 
achieved by the preparation and analysis of hydrolysates heated for periods of 24,48 and $72 \mathrm{~h}$, but it may be thought worth while to carry out such a trial in the future.

Comparison of the results from the single-column and two-column automatic analysers shows clearly that greater precision was achieved by the laboratories using the two-column system. It is not possible to offer a complete explanation of this finding, but several factors may have contributed to the less satisfactory performance of the single-column system. These include: the tendency of the base-line to rise towards the end of the analysis; the inability to separate certain amino acids, in particular lysine and tryptophan in laboratory no. 2 and lysine and histidine in laboratory no. 7; the use of a single internal reference standard, norleucine.

With the manual procedure good precision, comparable with that of the singlecolumn amino acid analysers, was achieved in laboratory no. 5, where the worker had had long experience of the method, but the precision achieved by the relatively inexperienced worker in laboratory no. 9 was markedly less good (c.f. Bender et al. 1959).

The determination of the cystine, methionine and tryptophan contents of proteins presents greater difficulty than that of the other amino acids because during acid hydrolysis tryptophan is virtually completely destroyed and oxidation and loss of cystine and methionine may readily occur. However, with the test proteins used in this trial it is apparent from Table 6 that there was comparatively little difference between the results of determinations of cystine and methionine in the protein hydrolysates (laboratories nos. 2, 4, 6, 7 and 8) and those determined after oxidation with performic acid (laboratories nos. I, 3, 5 and 9) by the procedure of Moore (1963) in which these amino acids are determined after oxidation to cysteic acid and methionine sulphone. It is evident that further trials are necessary to establish the most satisfactory procedure for the determination of these two amino acids.

\section{REFEREN CES}

Bender, A. E., Palgrave, J. A. \& Doell, B. H. (1959). Analyst 84, 526.

Bidmead, D. S. \& Ley, F. J. (1958). Biochim. biophys. Acta 29, 562.

Moore, S. ( 1963$)$. F. biol. Chem. 238, 235.

Moore, S., Spackman, D. H. \& Stein, W. H. (1958). Analyt. Chem. 30, 1185.

Moore, S. \& Stein, W. H. (195I). F. biol. Chem. 192, 663.

Moore, S. \& Stein, W. H. (1954a). F. biol. Chem. 2rr. 893 .

Moore, S. \& Stein, W. H. (r954b). F. biol. Chem. $211,907$.

Piez, K. A. \& Morris, L. (1960). Analyt. Biochem, r, 187.

Spackman, D. H., Stein, W. H. \& Moore, S. (1958). Analyt. Chem. 30, 190.

Spies, J. R. \& Chambers, D. C. (1949). Analyt. Chem. 21, 1249. 